\title{
EFFECTIVENESS OF DIFFERENT BNCT-DRUG INJECTION METHODS
}

\section{Vladimir Kanygin', Alphiya Tsygankova ${ }^{1,2^{*}}$, Aleksandr Kichigin', Evgenii Zavjalov",3, Ivan Razumov",3, Tatiana Guselnikova ${ }^{1,2}$, Anna Kasatova ${ }^{1,4}$, Roman Sibirtsev', Rinat Mukhamadiyarov ${ }^{5}$}

\author{
${ }^{1}$ Novosibirsk State University, Novosibirsk, Russia \\ ${ }^{2}$ Nikolaev Institute of Inorganic Chemistry SB RAS, Novosibirsk, Russia \\ 3Federal Research Center Institute of Cytology and Genetics SB RAS, Novosibirsk, Russia \\ 4Budker Institute of Nuclear Physics SB RAS, Novosibirsk, Russia \\ 5Research Institute for Complex Issues of Cardiovascular Diseases, Kemerovo, Russia
}

\begin{abstract}
The BNCT-drugs (BSH and BPA) toxicity for 8-10-week-old severe combined immunodeficiency (SCID) male mice outbred with SPF-status was studied. The possibility of increasing BPA (L-p-boron phenylalanine) and $B S H$ (sodium salt of borocaptate) therapeutic dose was shown. The relationship between a safe therapeutic dose and the administration method of BPA was found. The intraperitoneal injection allows one to increase the dose of BPA at least twice - $700 \mathrm{mg} / \mathrm{kg}$ b.w, BSH - at least 8 times, $800 \mathrm{mg} / \mathrm{kg}$ b.w with intraperitoneal injections. The BPA intraperitoneal and intratumoral injections demonstrate higher results in comparison with intravenous administration. The highest and statistically significant concentration of ${ }^{10} \mathrm{~B}$ in the tumor was found for intraperitoneal injection of $B P A$ for intratumoral injection of $B P A-27 \pm 5 \mu \mathrm{g} / \mathrm{g}$ (heterotopic tumors, $P=0.95$ ). The highest tumor/blood ratio for BPA was 7.5 for intratumoral administration in the point of 1 h (heterotopic tumors). The maximum concentration of ${ }^{10} \mathrm{~B}$ with the introduction of $\mathrm{BSH}$ was with intravenous administration and was $8 \pm 3 \mu \mathrm{g} / \mathrm{g}$ (orthotopic tumors). The highest tumor/blood ratio was 9.5 for intravenous injection in $1 \mathrm{~h}$ point (heterotopic tumors).
\end{abstract}

Keywords: BNCT, BSH, BPA, ISP-AES, therapeutic dose, toxic effect

\section{INTRODUCTION}

It is known that selective accumulation of boron-10 in cancer cells followed by epithermal neutron irradiation leads to death of tumor cells without affecting surrounding healthy cells. One of the problems of boron neutron capture therapy (BNCT) is the targeted delivery of boron to tumor cells. The effectiveness of the BNCT depends on many factors, including ${ }^{10} \mathrm{~B}$ drugs. These substances should satisfy the following conditions:

- non toxicity;

- accumulate mainly in a tumor with a tumor/normal tissue difference $>3: 1$ at doses of $\approx 20-35 \mu \mathrm{g} / \mathrm{g}{ }^{10} \mathrm{~B}$;

- $\quad$ quickly removed from the blood and normal tissues, but remaining in the tumor for several hours during neutron irradiation.

Currently, two low-molecular weight substances are used: BPA (L-p-boron phenylalanine) and BSH (sodium salt of borocaptate). Their therapeutic efficacy has been demonstrated in patients with high-grade gliomas, recurrent tumors of the head and neck, as well as melanoma. These BNCT-drugs meet the formulated requirements to a limited extent [1].
It has been previously shown that the oral method does not provide the necessary concentration gradient of the tumor/normal tissue [2]. Therefore, BPA in the fructose complex (BPA-f) intravenously were administered. In addition, it was found that prolonged BPA infusion increases the effectiveness of BNCT [3]. It should be noted that intravenous administration is the most commonly used method for BPA, BSH and other BNCT-drugs $[4,5,6,7]$. In some studies, the intraarterial administration was used, for example, a suspension of BSH with lipiodol in a rat model [8]. Along with intravenous administration, researchers often use intraperitoneal administration of BPA and BSH $[7,9,10]$. It is known that direct BNCT-drug injection into the tumor allows getting a high gradient of the tumor/normal tissue $[11,12,13]$.

The method of BNCT-drug injection is an important factor that can significantly change the tumor/normal tissue gradient. However, there are no systematic data on the effect of BNCT-drug administration methods on the tumor/normal tissue ratio. There is also no ordered data on the relationship of the administration methods with the possibility of increasing the BNCT-drug dose. All of this shows the necessity of further studies in this direction.

\footnotetext{
*alphiya@yandex.ru
} 


\section{MATERIALS AND METHODS}

All the experiments were carried out in compliance with the principles of humane treatment of animals in accordance with the directive of the European Union (86/609/EEC).

\subsection{Model heterotopic and orthotopic xenograft human glioblastoma: tumor induction}

The research has been done on 8-10-week-old severe combined immunodeficiency (SCID) male mice outbred with SPF-status. U87 human glioblastoma cell culture was obtained in the Center for Genetic Resources of Laboratory Animals, SPF Animal Farm, FRC IC\&G SB RAS. Cells were cultured on DMEM/F12 medium (1:1) (Biolot, Russia), 10\% fetal bovine serum (Gybco, USA), gentamicin $50 \mu \mathrm{g} / \mathrm{ml}$ (Dalchimpharm, Russia) at a temperature of $37^{\circ} \mathrm{C}$ and $5 \% \mathrm{CO}_{2}$. 18-21 days before the experiment. U87 human suspension of glioblastoma cells was prepared with the concentration of 100,000 cells per $1 \mu \mathrm{l}$.

For heterotopic xenograft cells, the suspension was injected subcutaneously into the right hind paw in a volume of $100 \mu \mathrm{l}$ (10 million cells per animal). For the orthotopic xenotransplantation of cells, intracranial inoculation of 500 thousand cells was performed using a stereotactic setup followed by the MRI. To confirm the presence of a tumor and measure its size, a BioSpec 117/16USR 11.7 $\mathrm{T}$ high-field tomograph was used. Using this technology tumor in mice survival are more than $80 \%$.

\subsection{Biodistribution studies}

Commercially available substances (previously enriched with $\left.{ }^{10} \mathrm{~B}\right)$, such as $\mathrm{BPA}\left(\mathrm{C}_{8} \mathrm{H}_{7} \mathrm{NH}_{2} \mathrm{COOH}-\right.$ $\left.\mathrm{B}(\mathrm{HO})_{2}\right)$ and $\mathrm{BSH}\left(\mathrm{Na}_{2} \mathrm{~B}_{12} \mathrm{H}_{11} \mathrm{SH}\right)$, were used as a boron monoisotopic ${ }^{10} \mathrm{~B}$ targeting delivery substance. Three administration protocols with different concentrations of BPA and BSH were assessed:

- intravenously (into the retro-orbital sinus);

- intraperitoneally;

- intratumorally.

To estimate BPA and BSH biodistribution the animals were euthanized, organs of interest were taken out and later frozen and kept at $\mathrm{T}=-20^{\circ} \mathrm{C}$.

Samples of blood, tumor, skin, brain, liver, kidney and spleen were processed for the total boron measurement by the Atomic Emission Spectrometry with Inductively Coupled Plasma (ICP-AES iCap-6500, Thermo). Boron determination in the organs is described in detail in [14].

\subsection{End-points}

The total boron concentration in tumor, blood and clinically relevant normal tissues were evaluated for each of the time-points. Individual tumor/blood and tumor/normal pouch boron concentration tissue ratios were calculated for each animal and then averaged for the animals in each group using formulas in [15].

\section{RESULTS}

\subsection{Toxic doses of the drugs}

The toxicity of standard drugs for BNCT was studied. The possibility of using BPA and BSH in the recommended maximum therapeutic doses on small laboratory animals was confirmed. They are 350 and $100 \mathrm{mg} / \mathrm{kg}$ body weight (b.w), accordingly. For the statistical reliability of the results, data obtained from five animals for the same concentration of the drug and injection method were used.

Intravenous injection (into the retro-orbital sinus) of BPA at a concentration from 700 and more $\mathrm{mg} / \mathrm{kg}$ resulted in the animal's death. At the same time, an intraperitoneal injection of a BPA dose of $700 \mathrm{mg} / \mathrm{kg}$ b.w, and $1050 \mathrm{mg} / \mathrm{kg} \mathrm{b.w} \mathrm{did} \mathrm{not} \mathrm{cause} \mathrm{toxic} \mathrm{effects.}$

For the BSH, we also used the intravenous and intraperitoneal injection method. According to the results of a long observation, the $\mathrm{BSH}$ in doses of 400, $600,800 \mathrm{mg} / \mathrm{kg}$ b.w (which exceeds the recommended therapeutic dose 4, 6 and 8 times, respectively) did not cause obvious toxic effects in the studied animals.

Thus, to ensure a higher concentration of the drugs in the tumor, the maximum therapeutic doses can be exceeded 3 times for BPA and 8 times for BSH.

\subsection{Comparison of the accumulation efficiency of $B P A$ and $B S H$ in orthotopic and heterotopic \\ tumors with intravenous injection}

This experiment was carried out under the conditions of recommended therapeutic drug doses $350 \mathrm{mg} / \mathrm{g}$ for $\mathrm{BPA}$ and $100 \mathrm{mg} / \mathrm{g}$ for $\mathrm{BSH}$. The administration into the retro-orbital sinus was performed.

Table 1 shows a comparison of the results of ${ }^{10} \mathrm{~B}$ determination by ICP-AES in the orthotopic tumor for $\mathrm{BPA}$ and $\mathrm{BSH}$ for all time points.

Table 1. The presence of ${ }^{10} \mathrm{~B}$ in the orthotopic tumor. Intravenous injection, $\mu \mathrm{g} / \mathrm{g}$

\begin{tabular}{|l|l|l|}
\hline Time point, $\mathrm{h}$ & BPA & BSH \\
\hline 0.5 & $10.9 \pm 0.4$ & $8 \pm 13$ \\
$\mathbf{1}$ & $\mathbf{1 4 . 1} \pm \mathbf{0 . 9} \#$ & $\mathbf{8} \pm \mathbf{3} \#$ \\
2 & $9.8^{*}$ & $3.4 \pm 0.4$ \\
4 & $7.2 \pm 1.5$ & $0.9 \pm 0.7$ \\
8 & $4.3^{*}$ & $0.2 \pm 0.2$ \\
12 & $3.4 \pm 0.1$ & not detected ${ }^{* *}$ \\
24 & $0.33 \pm 0.09$ & not detected \\
\hline
\end{tabular}

limit of detection method; \# - a statistically significant $(\mathrm{P}=0.95)$.

It should be noted that the accumulation efficiency of ${ }^{10} \mathrm{~B}$ in the tumor for BPA is higher than for $\mathrm{BSH}$. The $1 \mathrm{~h}$ point is highlighted in bold, the concentration ${ }^{10} \mathrm{~B}$ is the highest for it. Results for BPA and $\mathrm{BSH} 1 \mathrm{~h}$ have a statistically significant difference $(\mathrm{P}=0.95)$. For BPA, the tumor/brain ratio at this point is 4.4 ; tumor/blood - 3.0. For BSH, the tumor/brain ratio at this point is 3.5; tumor/blood - 0.42 .

Table 2 shows a comparison of the results of ${ }^{10} \mathrm{~B}$ determination by ICP-AES in the heterotopic tumor for $\mathrm{BPA}$ and BSH for all time points. For a heterotopic tumor, the efficiency of ${ }^{10} \mathrm{~B}$ accumulation in a tumor for $\mathrm{BPA}$ is higher than for BSH as well as for orthotopic tumors. The $1 \mathrm{~h}$ point is highlighted in bolt, the concentration of ${ }^{10} \mathrm{~B}$ is the highest for it. BSH-result for $1 \mathrm{~h}$ has a statistically significant difference $(\mathrm{P}=0.95)$. For BPA, the tumor/brain ratio at this point is 2.4; tumor/blood - 1.4. For BSH, the tumor/brain ratio at this point is 9.5; tumor/blood -0.47 . 
Table 2. The presence of ${ }^{10} \mathrm{~B}$ in the heterotopic tumor. Intravenous injection, $\mu \mathrm{g} / \mathrm{g}$.

\begin{tabular}{|l|l|l|}
\hline Time point, $\mathrm{h}$ & BPA & BSH \\
\hline $\mathbf{1}$ & $\mathbf{1 2} \pm \mathbf{5}$ & $\mathbf{6} \pm \mathbf{1} \#$ \\
$\mathbf{2}$ & $\mathbf{1 1} \pm \mathbf{4}$ & $1 \pm 2$ \\
3 & $8 \pm 2$ & $3 \pm 1$ \\
4 & $4 \pm 2$ & $1.1 \pm 0.6$ \\
\hline
\end{tabular}

\# - a statistically significant $(\mathrm{P}=0.95)$.

A high gradient tumour/normal tissue boron distribution for $\mathrm{BSH}$ for heterotopic tumors is noteworthy. However, in both cases (orthotopic and heterotopic tumor) the error in determining the $\mathrm{BSH}$ is higher than for BPA. Figure 1 presents a comparison of the found ${ }^{10} \mathrm{~B}$ concentration in tumor for a point of $1 \mathrm{~h}$.

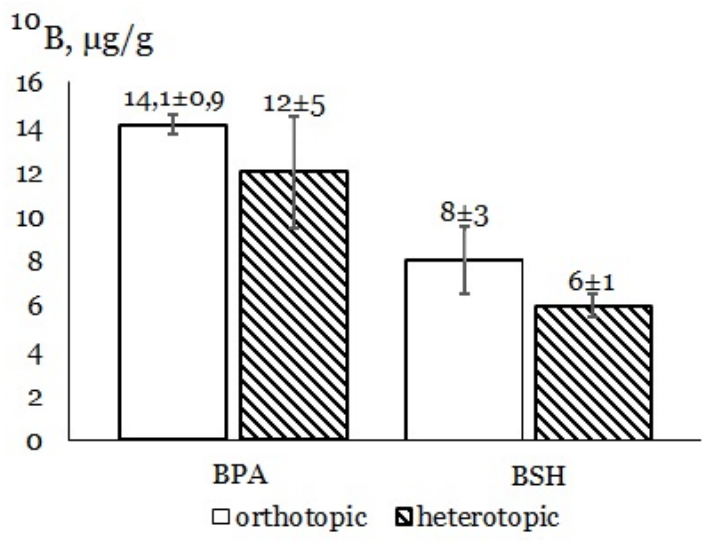

Figure 1. Comparison of the ${ }^{10} \mathrm{~B}$ concentration in the tumor for a point of $1 \mathrm{~h}, \mu \mathrm{g} / \mathrm{g}(\mathrm{n}=3, \mathrm{P}=0.95)$

The difference in boron concentration values has statistically significant for orthotopic tumors at injection BPA $(14.1 \pm 0.9 \mu \mathrm{g} / \mathrm{g})$ and $\mathrm{BSH}(8 \pm 3 \mu \mathrm{g} / \mathrm{g})$; $(\mathrm{P}=0.95)$. Also the difference in boron concentration values has statistically significant for heterotopic tumors at injection BPA $(12 \pm 5 \mu \mathrm{g} / \mathrm{g})$ and $\mathrm{BSH}$ $(6 \pm 1 \mu \mathrm{g} / \mathrm{g}) ;(\mathrm{P}=0.95)$. The tumor/brain ratio at this point for BPA is 4.4 (ortho) and 2.4 (hetero). Then, for $\mathrm{BSH}$ tumor/brain the ratio is 3.5 and 9.5 (ortho and hetero, respectively).

\subsection{Comparison of the accumulation efficiency of $B P A$ and $B S H$ in heterotopic tumors with intraperitoneally injection}

This experiment was carried out under the conditions of recommended therapeutic drugs doses $350 \mathrm{mg} / \mathrm{g}$ b.w for BPA and $100 \mathrm{mg} / \mathrm{g}$ b.w for BSH. The intraperitoneal administration was performed.

Table 3. The presence of ${ }^{10} \mathrm{~B}$ in the heterotopic tumor. Intraperitoneal injection, $\mu \mathrm{g} / \mathrm{g}$.

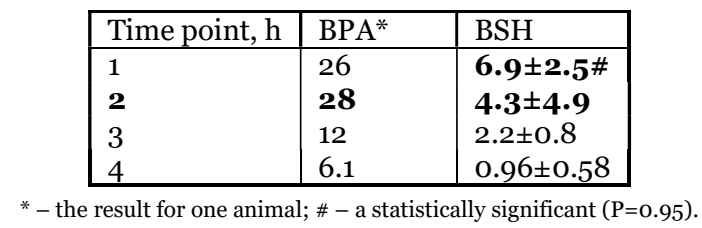

Table 3 shows a comparison of the results of ${ }^{10} \mathrm{~B}$ determination by ICP-AES in the heterotopic tumor for $\mathrm{BPA}$ and BSH for all time points - 1, 2, 3 and $4 \mathrm{~h}$. For heterotopic, the accumulation efficiency of ${ }^{10} \mathrm{~B}$ for BPA is higher than for $\mathrm{BSH}$. The $2 \mathrm{~h}$ point for $\mathrm{BPA}$ is highlighted in bolt; the concentration ${ }^{10} \mathrm{~B}$ is the highest for it. The tumor/blood ratio in $1 \mathrm{~h}$ point is 3.4 . The $1 \mathrm{~h}$ and $2 \mathrm{~h}$ points for $\mathrm{BSH}$ are highlighted in bolt. The tumor/blood ratio at this point is 0.28 .

\subsection{Comparison of the accumulation efficiency of $B P A$ and $B S H$ in heterotopic tumors with intratumoral injection}

This experiment was carried out under the conditions of recommended therapeutic drug doses $350 \mathrm{mg} / \mathrm{g}$ b.w for BPA and $100 \mathrm{mg} / \mathrm{g} \mathrm{b.w}$ for BSH. The intratumoral administration was performed.

Table 4 shows a comparison of the results of ${ }^{10} \mathrm{~B}$ determination by ICP-AES in the heterotopic tumor for BPA and BSH for all time points $-1,2,3$ and $4 \mathrm{~h}$. For heterotopic, the accumulation efficiency of ${ }^{10} \mathrm{~B}$ for BPA is higher than for $\mathrm{BSH}$. The $2 \mathrm{~h}$ point for $\mathrm{BPA}$ is highlighted in bolt; the concentration of ${ }^{10} \mathrm{~B}$ is the highest for it. The tumor/blood ratio in $1 \mathrm{~h}$ point is 7.5 . The $1 \mathrm{~h}$ point for $\mathrm{BSH}$ is highlighted in bolt. The tumor/blood ratio at this point is 0.57 .

Table 4 . The presence of ${ }^{10} \mathrm{~B}$ in

the heterotopic tumor. Intratumoral injection, $\mu \mathrm{g} / \mathrm{g}$

\begin{tabular}{|l|l|l|}
\hline Time point, $\mathrm{h}$ & BPA & BSH \\
\hline 1 & $16 \pm 10$ & $6 \pm 3$ \\
$\mathbf{2}$ & $\mathbf{2 7 \pm 5 \#}$ & $\mathbf{9} \pm \mathbf{5}$ \\
3 & $9.9 \pm 0.4$ & $6 \pm 3$ \\
4 & $10.1 \pm 0.5$ & $3.2 \pm 0.5$ \\
\hline
\end{tabular}

\# - a statistically significant $(\mathrm{P}=0.95)$.

\section{DisCUSSION}

We showed that the use of BPA and BSH for human glioblastoma U87 can be promising if it is possible to increase the concentration of ${ }^{10} \mathrm{~B}$ in the brain. It is known that the prolonged administration of the drugs is used in BNCT [16]. However, our studies have shown that the highest concentration of boron in the tumor accumulates for 1-2 hours after drug administration (see tables 1-4), while the type of drugs and administration method have an effect on the ratio of tumor/normal tissue.

For intravenous injections in case of BPA, the difference for the found concentration of ${ }^{10} \mathrm{~B}$ for various types of tumors is not significant $-14.1 \pm 0.9$ and $12 \pm 5 \mu \mathrm{g} / \mathrm{g}$. For BSH, we see the same results: within the confidence interval, the results coincide $-8 \pm 3$ and $6 \pm 1 \mu \mathrm{g} / \mathrm{g}$.

When comparing the effectiveness of various BPA administration methods, it should be noted:

- the highest concentration of ${ }^{10} \mathrm{~B}$ in the tumor was found for intraperitoneal injection $28 \mu \mathrm{g} / \mathrm{g}$ (heterotopic tumors) and for intratumoral injection - $27 \pm 5 \mu \mathrm{g} / \mathrm{g}$ (heterotopic tumors), see Figure 2;

- the highest tumor/blood ratio is 7.5 for intratumoral administration in $1 \mathrm{~h}$ point (heterotopic tumors).

The difference in boron concentration values has statistically significant for heterotopic tumors at 
intravenous $(12 \pm 1 \mu \mathrm{g} / \mathrm{g})$ and intratumorally $(27 \pm 5$ $\mu \mathrm{g} / \mathrm{g})$ injection $(\mathrm{P}=0.95)$.

In addition, an intraperitoneal injection of a dose of BPA of $700 \mathrm{mg} / \mathrm{kg}$ and $1050 \mathrm{mg} / \mathrm{kg}$ b.w did not cause toxic effects. Therefore, when using higher doses of $\mathrm{BPA}$, an increase in the accumulated concentration of ${ }^{10} \mathrm{~B}$ in the tumor can be expected up to $36 \mu \mathrm{g} / \mathrm{g}$ at least.

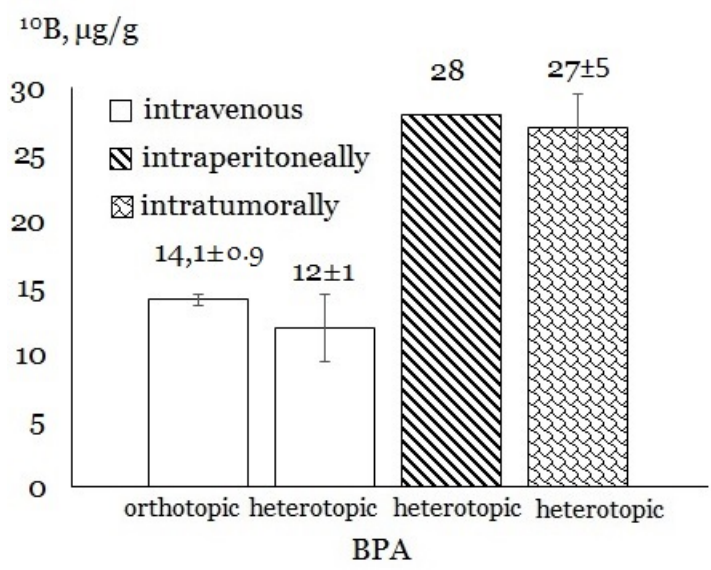

Figure 2. Comparison of the ${ }^{10} \mathrm{~B}$ concentration in the tumor for various injection methods, $\mu \mathrm{g} / \mathrm{g}(\mathrm{n}=1-3, \mathrm{P}=0.95)$

When comparing the effectiveness of various $\mathrm{BSH}$ administration methods, it should be noted:

- the tumor/blood ratio is less than 1.0 with any method of administering the drugs;

- the highest concentration of ${ }^{10} \mathrm{~B}$ in the tumor was found for intravenous injection $8 \pm 3 \mu \mathrm{g} / \mathrm{g}$ (orthotopic tumors), see Figure 3;

- the highest tumor/blood ratio is 9.5 for intravenous injection in $1 \mathrm{~h}$ point (heterotopic tumors).

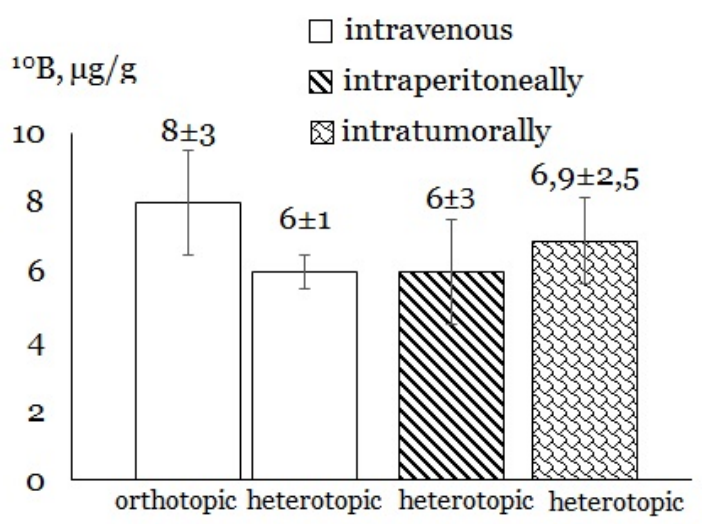

BSH

Figure 3. Comparison of the ${ }^{10} \mathrm{~B}$ concentration in the tumor for various injection methods, $\mu \mathrm{g} / \mathrm{g}(\mathrm{n}=3, \mathrm{P}=0.95)$

It can be seen that the ${ }^{10} \mathrm{~B}$ concentration in the tumor coincides within the confidence interval for three injection methods and does not exceed the value of $8 \mu \mathrm{g} / \mathrm{g}$ (the difference in boron concentration values is statistically insignificant). As in the case of BPA for
$\mathrm{BSH}$, the therapeutic dose can be increased to 800 $\mu \mathrm{g} / \mathrm{g}$. Therefore, an increase in the accumulated concentration of ${ }^{10} \mathrm{~B}$ in the tumor can also be expected when using higher drug doses of up to $48 \mu \mathrm{g} / \mathrm{g}$ at least.

\section{CONCLUSION}

To ensure a higher concentration of drugs in the tumor, the maximum therapeutic doses can be exceeded 3 times for BPA and 8 times for BSH. This is possible with intraperitoneal or intratumoral administration of BPA and with intraperitoneal administration of BSH.

The highest and statistically significant concentration of ${ }^{10} \mathrm{~B}$ in the tumor was found for intraperitoneal injection of $\mathrm{BPA}$ for intratumoral injection of BPA $-27 \pm 5 \mu \mathrm{g} / \mathrm{g}$ (heterotopic tumors, $\mathrm{P}=0.95)$. The maximum concentration of ${ }^{10} \mathrm{~B}$ with the introduction of BSH was with intravenous administration and it was $8 \pm 3 \mu \mathrm{g} / \mathrm{g}$ (orthotopic tumors).

Using the increased doses in combination with the intratumoral or intraperitoneal method of drug administration, we can increase the effectiveness of BNCT for glioblastoma U87.

Acknowledgements: The paper is a part of the research done within the project supported by the Russian Foundation for Basic Research in the framework of the research project $N^{\circ} 18-29-01007$. The authors would like to thank the Center for Genetic Resources of Laboratory Animals, SPF Animal Farm, FRC IC\&G SB RAS.

\section{REFERENCES}

1. Neutron Capture Therapy: Principles and Applications, W. A. G. Sauerwein, A. Wittig, R. Moss, Y. Nakagawa, Eds., 1st ed., Berlin, Germany: SpringerVerlag, 2012, ch. 6, pp. $366-531$. DOI: $10.1007 / 978-3-642-31334-9$

2. P. M. Busse et al., "The Harvard-MIT BNCT Program: Overview of the Clinical Trials and Translational Research," in Frontiers in Neutron Capture Therapy, vol. 1, M. F. Hawthorne, K. Shelly, R. J. Wiersema, Eds., 1st ed., Boston (MA), USA: Springer, 2001, ch. 2, pp. $37-60$.

DOI: $10.1007 / 978-1-4615-1285-1$

3. K. Skold et al., "Boron Neutron Capture Therapy for glioblastoma multiforme: advantage of prolonged infusion of BPA-f," Acta. Neurol. Scand., vol. 122, no. 1, pp. $58-62$, Jul. 2010.

DOI: 10.1111/j.1600-0404.2009.01267.x.

PMid: 19951268

4. R. Henriksson et al., "Boron neutron capture therapy (BNCT) for glioblastoma multiforme: a phase II study evaluating a prolonged high-dose of boronophenylalanine (BPA)," Radiother. Oncol., vol. 88, no. 2, pp. 183 - 191, Aug. 2008.

DOI: 10.1016/j.radonc.2006.04.015 PMid: 18336940

5. T. Yamamoto et al., "Current clinical results of the Tsukuba BNCT trial," Appl. Radiat. Isot., vol. 61, no. 5, pp. 1089 - 1093, Nov. 2004.

DOI: 10.1016/j.apradiso.2004.05.010 PMid: 15308197

6. R. Bergland, E. Elowitz, J. A. Coderre, D. Joel, M. Chadha, "A Phase 1 Trial of Intravenous Boronophenylalanine-Fructose Complex in Patients 
with Glioblastoma Multiforme," in Cancer Neutron Capture Therapy, Y. Mishima, Eds., 1st ed., Boston (MA), USA: Springer, 1996, ch. 5, pp. $739-745$. DOI: $10.1007 / 978-1-4757-9567-7 \_105$

7. M. A. Garabalino et al., "Boron neutron capture therapy (BNCT) for the treatment of liver metastases: biodistribution studies of boron compounds in an experimental model," Radiat. Environ. Biophys., vol. 50, no. 1, pp. 199 - 207, Mar. 2011.

DOI: $10.1007 /$ s00411-010-0345-6 PMid: 21132507

8. M. Suzuki et al., "Intra-arterial administration of sodium borocaptate (BSH)/lipiodol emulsion delivers B-10 to liver tumors highly selectively for boron neutron capture therapy: experimental studies in the rat liver model," Int. J. Radiat. Oncol. Biol. Phys., vol. 59, no. 1, pp. 260 - 266, May 2004

DOI: 10.1016/j.ijrobp.2003.12.018 PMid: 15093923

9. M. A. Garabalino et al., "Boron biodistribution for BNCT in the hamster cheek pouch oral cancer model: combined administration of BSH and BPA," Appl. Radiat. Isot., vol. 88, pp. $64-68$, Jun. 2014.

DOI: 10.1016/j.apradiso.2013.11.118 PMid: 24360859

10. K. Yokoyama et al., "Pharmacokinetic study of BSH and BPA in simultaneous use for BNCT," $J$. Neurooncol., vol. 78 , no. 3, pp. 227 - 232, Jul. 2006.

DOI: $10.1007 / \mathrm{s} 11060-005-9099-4$ PMid: 16557351

11. R. F. Barth et al., "Neutron capture therapy of epidermal growth factor $(+)$ gliomas using boronated cetuximab (IMC-C225) as a delivery agent," Appl. Radiat. Isot., vol. 61, no. 5, pp. 899 - 903, Nov. 2004.
DOI: 10.1016/j.apradiso.2004.05.004 PMid: 15308165

12. R. F. Barth et al., "Molecular targeting of the epidermal growth factor receptor for neutron capture therapy of gliomas," Cancer Res., vol. 62, no. 11, pp. 3159 - 3166, Jun. 2002.

PMid: 12036929

13. W. Yang, R. F. Barth, D. M. Adams, A. H. Soloway, "Intratumoral delivery of boronated epidermal growth factor for neutron capture therapy of brain tumors," Cancer Res., vol. 57, no. 19, pp. 4333 - 4339, Oct. 1997. PMid: 9331095

14. A. R. Tsygankova et al., "Determination of boron by inductively coupled plasma atomic emission spectroscopy. Biodistribution of $10 \mathrm{~B}$ in tumor-bearing mice," Russ. Chem. Bull., vol.69, no. 3, pp. $601-607$, Mar. 2020.

DOI: $10.1007 / \mathrm{s} 11172-020-2805-8$

15. S. P. Hozo, B. Djulbegovic, I. Hozo, "Estimating the mean and variance from the median, range, and the size of a sample," BMC Medical Res. Methodol., vol. 5, no. 13, pp. 13 - 23, Apr. 2005.

DOI: $10.1186 / 1471-2288-5-13 \mathrm{~A}$

PMid: 15840177

PMCid: PMC1097734

16. R. Henriksson et al., "Boron neutron capture therapy (BNCT) for glioblastoma multiforme: a phase II study evaluating a prolonged high-dose of boronophenylalanine (BPA)," Radiother. Oncol., vol. 88, no. 2, pp. 183 - 191, Aug. 2008.

DOI: 10.1016/j.radonc.2006.04.015

PMid: 18336940 